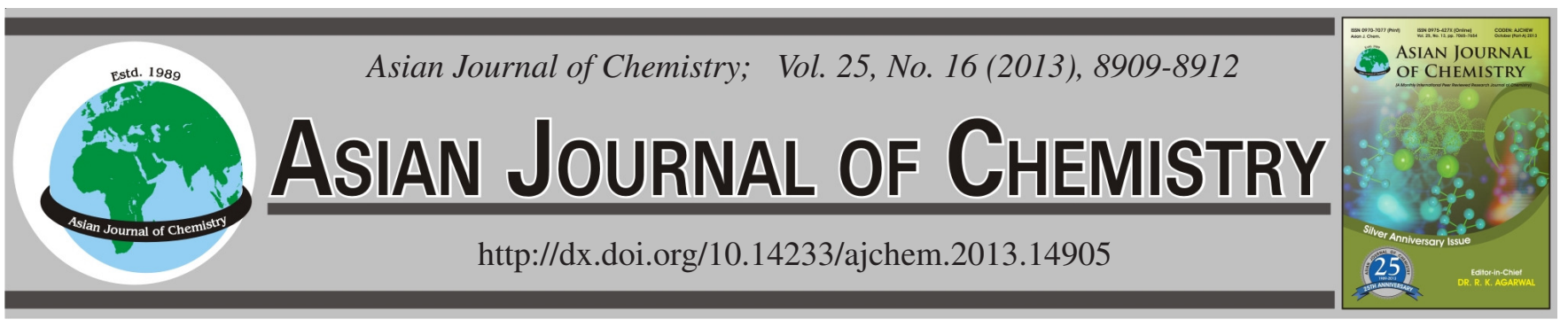

\title{
Determination of Volatile Organic Compounds in Pepper Seeds by GC/MS
}

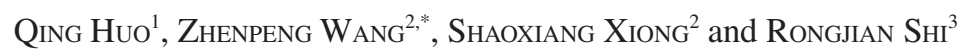

${ }^{1}$ Biochemical Engineering College of Beijing Union University, Beijing 100023, P.R. China

${ }^{2}$ Institute of Chemistry, Chinese Academy of Sciences, Beijing 100190, P.R. China

${ }^{3}$ Institute of High Energy Physics, Chinese Academy of Sciences, Beijing 100049, P.R. China

*Corresponding author: Tel: +86 10 62554495; E-mail: huo_q2002@yahoo.com.cn

(Received: 4 December 2012;

Accepted: 9 September 2013)

AJC-14078

This experiment studies the volatile ingredients of pepper seeds which are from Shanxi and Sichuan Provinces by GC/MS instrument. |
The data compares with the standard spectrum through computer retrieval, identifies main ingredient of two origin pepper seeds. The
results show that the pepper seeds contain mainly $\alpha$-hydroxypropionate, glycerol, gluconic acid, twenty-one-carbon unsaturated fatty
acids, disaccharides and squalene. Squalene in Sichuan pepper seeds has higher contents than it in Shanxi pepper seeds.
Key Words: GC/MS instrument, Pepper seeds, Squalene.

\section{INTRODUCTION}

Gas chromatography and mass spectrometry have much in common, so the two analytical techniques can be used in combination. The processes of gas chromatography separation and mass spectrometry analysis are conducted in the gaseous state. The boiling range of compounds which is analyzed in gas chromatographic is available for mass spectrometric analysis; gas chromatography and mass spectrometry have similar requirements of the sample preparation and pre-treatment. Both techniques of gas chromatography and mass spectrometry analysis are ideal ways to analyze mixture. Because of these common features, chromatography and mass spectrometry can become a union system almost without structure change.

Techniques of combined gas chromatography-mass spectrometry developed mainly to solve the following three questions: (1) Gas chromatographic columns pressure at the outlet matches the required high vacuum when mass spectrometry working properly; (2) MS scan speed and peak time outflow adapt to each other; (3) Chromatography and mass spectrometry signal simultaneously detected, so we can get complete chromatography and mass spectra. Therefore, the GC/MS benefit from the technical development and improvement in gas chromatography and mass spectrometer performance improved ${ }^{1-4}$.

Pepper belongs to the Solanaceae medicinal plants, the fruit is edible, roots can be used as medicine. In recent years, with the in-depth study, the pepper's research has not only in the traditional food and medicinal. The fruit of pepper contains a variety of chemicals to maintain the body's normal physiological function and enhance the body's resistance and vitality ${ }^{5,6}$. Peppers have been found the chemical composition of terpenes, steroids, alkaloids, flavonoids, polysaccharides, unsaturated fatty acids, etc. Currently, pepper seeds research has focused on its antioxidant activity, there are little research on composition of fat and its extract. Pepper seed content of about 20 to $30 \%$ oil, comparable or higher with soybean oil content and linoleic acid is a high proportion, wherein the unsaturated fatty acids linoleic acid and oleic acid content is relatively high. The pepper seeds also contain effective substances such as polymerized lipid pigment, phospholipids, sterols, hydrocarbons and fat-soluble vitamins, etc. In addition to containing the oil, protein, crude fiber, pepper seeds also contain a certain amount of capsaicin. Thus, study on pepper seed oil composition and extraction has important significance.

\section{EXPERIMENTAL}

Pepper seeds which are from Shanxi and Sichuan Provinces purchased from the local market. The Chemicals viz., $n$ hexane, chloroform, ethanol, pyridine (CP, Beijing chemical plant), $1 \%$ trimethyl-chlorosilane bis(trimethylsilyl) trichloroacetamide are purchased from Fluka Co..

Shimadzu GCMS-QP2010 gas chromatography mass spectrometry, Chromatographic conditions: Column Model: HP-5ms capillary column $30 \mathrm{~m}, 0.32 \mathrm{~mm}$; Split ratio:10:1; Inlet temperature: $250^{\circ} \mathrm{C}$; MS conditions: Ion source temperature: $200^{\circ} \mathrm{C}$; Electron energy: $70 \mathrm{eV}$; Scan range: 20-650 m/z, EI ion source, KQ-250B ultrasonic cleaner, CVE-2000 rotary evaporator. 


\section{RESULTS AND DISCUSSION}

Sample analysis results obtained with three different solvent extracted from pepper seeds: Weigh quantitative peppers which are from Shanxi and Sichuan Provinces, crush, grind, then weighed and equally divided into three tubes. The same volume of three different solvents placed in the three sample tubes, they are $n$-hexane, chloroform and ethanol. The sample ultrasonic $0.5 \mathrm{~h}$ in ultrasonic cleaning, soak for $24 \mathrm{~h}$, remove the upper liquid, filter, $1 \mu \mathrm{L}$ fed into the GC/MS instrument by $10 \mu \mathrm{L}$ syringe (Fig. 1).

In Fig. 1, top to bottom curves as follows: the results of the $n$-hexane extraction, chloroform extraction and ethanol extraction of Shanxi pepper seeds; $n$-hexane extraction, chloroform extraction and ethanol extraction of Sichuan pepper seeds. There is no significant component peak in the spectrum, all of its peaks are impurity peaks, so we suspect to have large polar high boiling substances exist. So try to use the silylating reagent, derivatives of highly polar compounds in the sample and then GC/MS analysis.

Results of the analysis on the three different solvent pepper seed extract samples after the silanized reaction: The extraction solvent obtained from 3.1 spin dry by rotary evaporator, $2 \mathrm{~mL}$ pyridine solution is added to dissolve the sample, then add $2 \mathrm{~mL}$ silylating agent, stand at room temperature for $24 \mathrm{~h}$, wait for the full reaction. $1 \mu \mathrm{L}$ fed into the $\mathrm{GC} /$ MS instrument (Fig. 2).
Fig. 2 showed the results of silanized samples total ion current (TIC) chromatogram, top to bottom curves as follows: the results of the $n$-hexane extraction, chloroform extraction and ethanol extraction of Shanxi pepper seeds; $n$-hexane extraction, chloroform extraction and ethanol extraction of Sichuan pepper seeds. 18 kinds of main components in the sample are isolated by gas chromatography, the detailed scan results are shown in Table-1.

\begin{tabular}{|c|c|c|c|}
\hline \multicolumn{4}{|c|}{$\begin{array}{l}\text { TABLE-1 } \\
\text { ANALYSIS RESULTS OF SAMPLE BY GC/MS }\end{array}$} \\
\hline No. & Chemical composition & m.f. & m.w. \\
\hline 1 & Oxalic acid & $\mathrm{C}_{2} \mathrm{H}_{2} \mathrm{O}_{4}$ & 90 \\
\hline 2 & $\alpha$-Hydroxypropionic acid & $\mathrm{C}_{3} \mathrm{H}_{6} \mathrm{O}$ & 180 \\
\hline 3 & Butanediol & $\mathrm{C}_{4} \mathrm{H}_{10} \mathrm{O}_{2}$ & 90 \\
\hline 4 & $\alpha$-Ethyl hexanoate & $\mathrm{C}_{8} \mathrm{H}_{16} \mathrm{O}_{2}$ & 144 \\
\hline 5 & Glycerin & $\mathrm{C}_{3} \mathrm{H}_{8} \mathrm{O}_{3}$ & 92 \\
\hline 6 & Phosphate & $\mathrm{H}_{3} \mathrm{O}_{4} \mathrm{P}$ & 98 \\
\hline 7 & Erythritol & $\mathrm{C}_{4} \mathrm{H}_{10} \mathrm{O}_{4}$ & 122 \\
\hline 8 & 12 Carbon fatty acids & $\mathrm{C}_{12} \mathrm{H}_{24} \mathrm{O}_{2}$ & 203 \\
\hline 9 & Butenedioic & $\mathrm{C}_{4} \mathrm{H}_{4} \mathrm{O}_{4}$ & 116 \\
\hline 10 & Glucopyranose & $\mathrm{C}_{6} \mathrm{H}_{12} \mathrm{O}_{6}$ & 180 \\
\hline 11 & Gluconate & $\mathrm{C}_{6} \mathrm{H}_{10} \mathrm{O}_{7}$ & 194 \\
\hline 12 & 16 Carbon fatty acids & $\mathrm{C}_{16} \mathrm{H}_{32} \mathrm{O}_{2}$ & 256 \\
\hline 13 & 21 Carbon unsaturated fatty acids & $\mathrm{C}_{18} \mathrm{H}_{32} \mathrm{O}_{2}$ & 280 \\
\hline 14 & 21 Carbon saturated fatty acids & $\mathrm{C}_{18} \mathrm{H}_{36} \mathrm{O}_{2}$ & 284 \\
\hline 15 & Disaccharide & $\mathrm{C}_{12} \mathrm{H}_{22} \mathrm{O}_{11}$ & 342 \\
\hline 16 & Palmitic acid glyceride & $\mathrm{C}_{18} \mathrm{H}_{36} \mathrm{O}_{4}$ & 316 \\
\hline 17 & Squalene & $\mathrm{C}_{30} \mathrm{H}_{50}$ & 410 \\
\hline 18 & Steroid & $\mathrm{C}_{27} \mathrm{H}_{46} \mathrm{O}_{4}$ & 386 \\
\hline
\end{tabular}

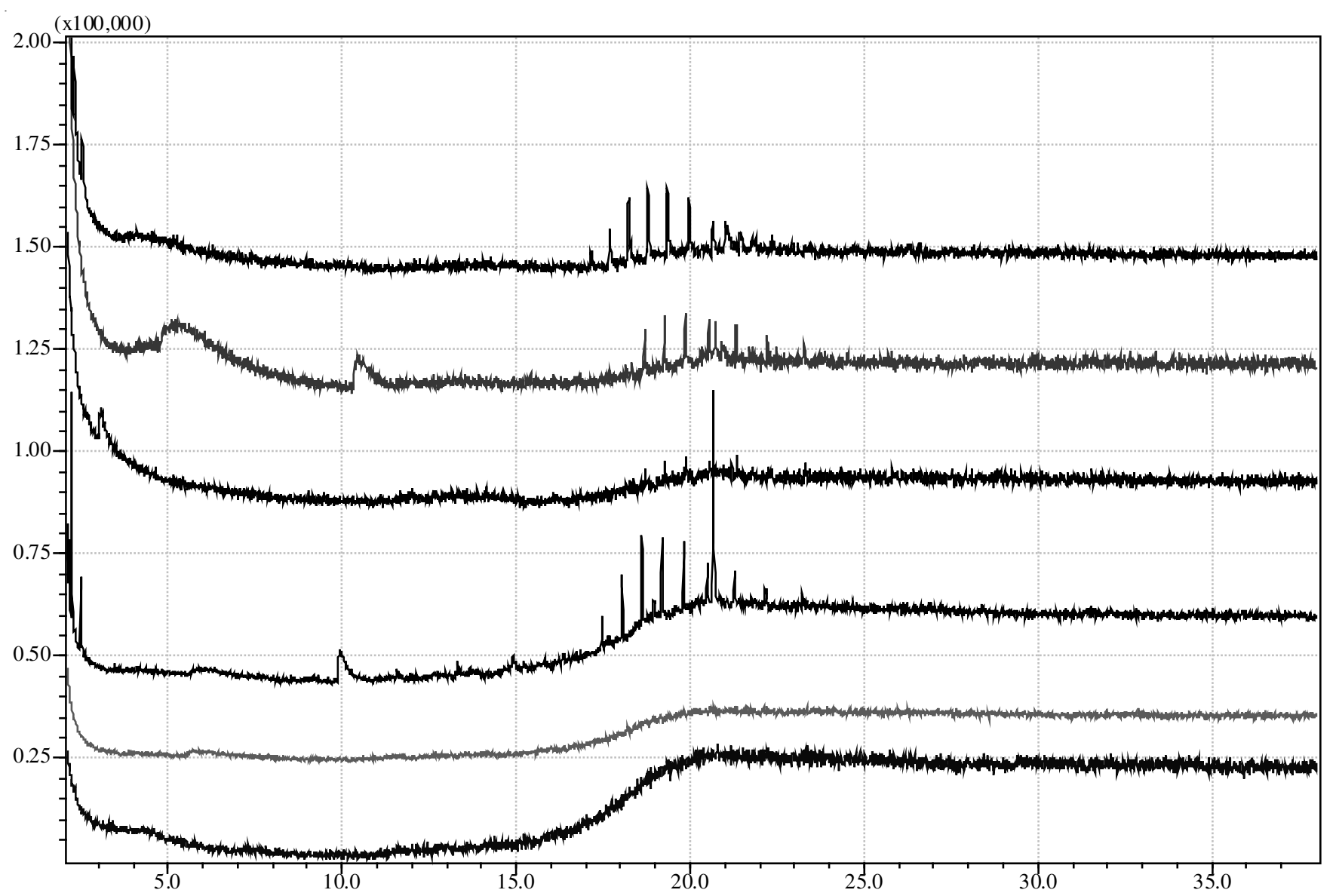

Fig. 1. Comparison chart of the six samples of total ion current (TIC) chromatogram 


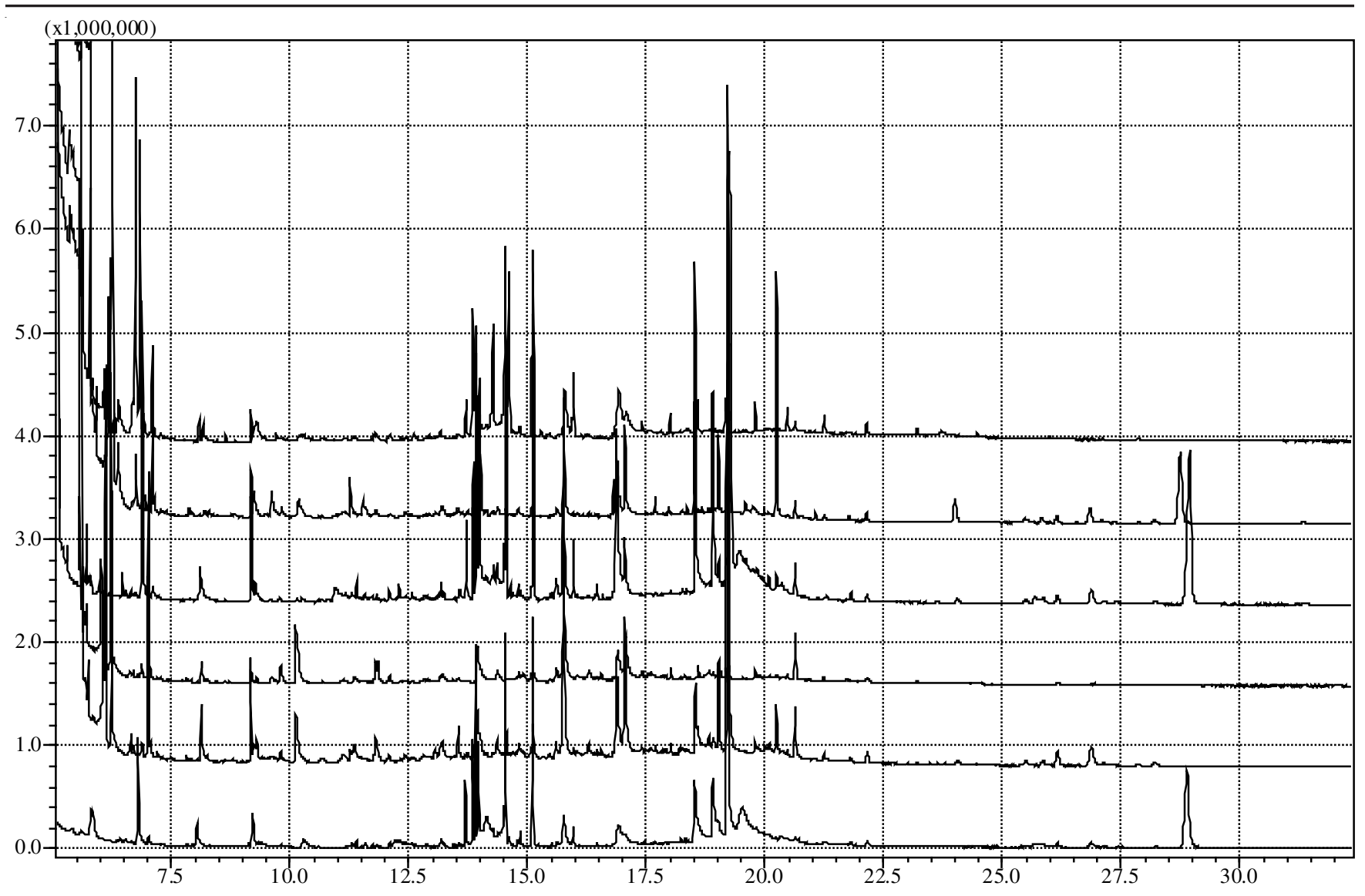

Fig. 2. Comparison chart of the six silanized samples of total ion current (TIC) chromatogram

Silylation treatment of the sample can reduce the boiling point of the component, make it fully gasified and can also reduce the tailing of the gas chromatograph, achieve a better separation effect. The pepper seeds contain squalene, which was not reported before (Table-1).

Squalene is also called 30 carbon hexaene, squalene or 2,6,10,15,19,23-hexamethyl-2,6,10,14,18,22-24 carbon hexaene. Its main functions are: (1) Promote blood circulation, prevention and treatment of high blood pressure, heart disease and stroke; (2) Antiinflammatory and sterilization: It can prevent and treat the diseases caused by bacteria, such as colds, skin diseases, etc. (3) Activation of bodily functions cell: It can prevent and treat the lesions caused by hypoxia, comprehensively enhance physical fitness, antiaging, improve immunity resistance to disease (including cancer). (4) Repair cells, accelerate wound healing: In view of it has a number of positive features, so squalene has higher development value.

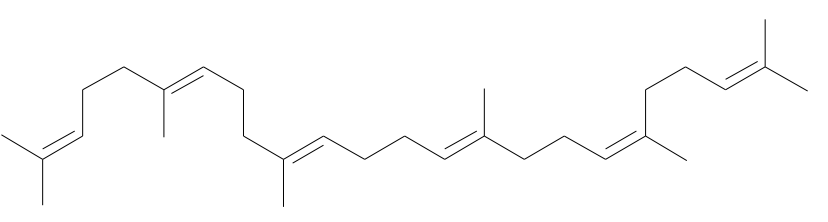

$$
\text { squalene }
$$

$$
\mathrm{C}_{30} \mathrm{H}_{50}
$$

Exact Mass: 410.39125

Mol. Wt.: 410.71800

$\mathrm{m} / \mathrm{e}: 410.39125$ (100.0\%), 411.39461 (33.4\%), 412.39796 (5.4\%)

C, 87.73; H, 12.27
Compare the squalene content of pepper seeds from different producing areas: The results of silanized samples total ion current (TIC) chromatogram, from top to bottom curves as follows (Fig. 3): the $n$-hexane extraction, chloroform extraction and ethanol extraction of Shanxi pepper seeds; $n$-hexane extraction, chloroform extraction and ethanol extraction of Sichuan pepper seeds. The peak appearing on the $20.65^{\text {th }}$ min has been proved to be squalene by MS shown in Fig. 4. Squalene contents of various extracts from pepper seeds were given in Table-2.

\begin{tabular}{clc}
\multicolumn{3}{c}{ TABLE-2 } \\
SQUALENE CONTENT OF VARIOUS \\
EXTRACTS FROM PEPPER SEEDS \\
\hline \multicolumn{2}{c}{ Sample } & Squalene content (\%) \\
\hline Pepper seeds from & $n$-Hexane extraction & 0.41 \\
Shanxi producing & Chloroform extraction & 0.62 \\
areas & Ethanol extraction & 0.64 \\
\hline Pepper seeds from & $n$-Hexane extraction & 4.35 \\
Sichuan producing & Chloroform extraction & 1.68 \\
areas & Ethanol extraction & 0.19 \\
\hline
\end{tabular}

We can see from Table-2, the squalene content in Sichuan pepper seed is higher than that in Shanxi pepper seed.

\section{Conclusion}

This paper analyzes different origin pepper seeds of volatile organic compounds using gas chromatography and mass spectrometry (GC/MS). Silylation treatment can make the sample fully gasified and have a better separation effect. 


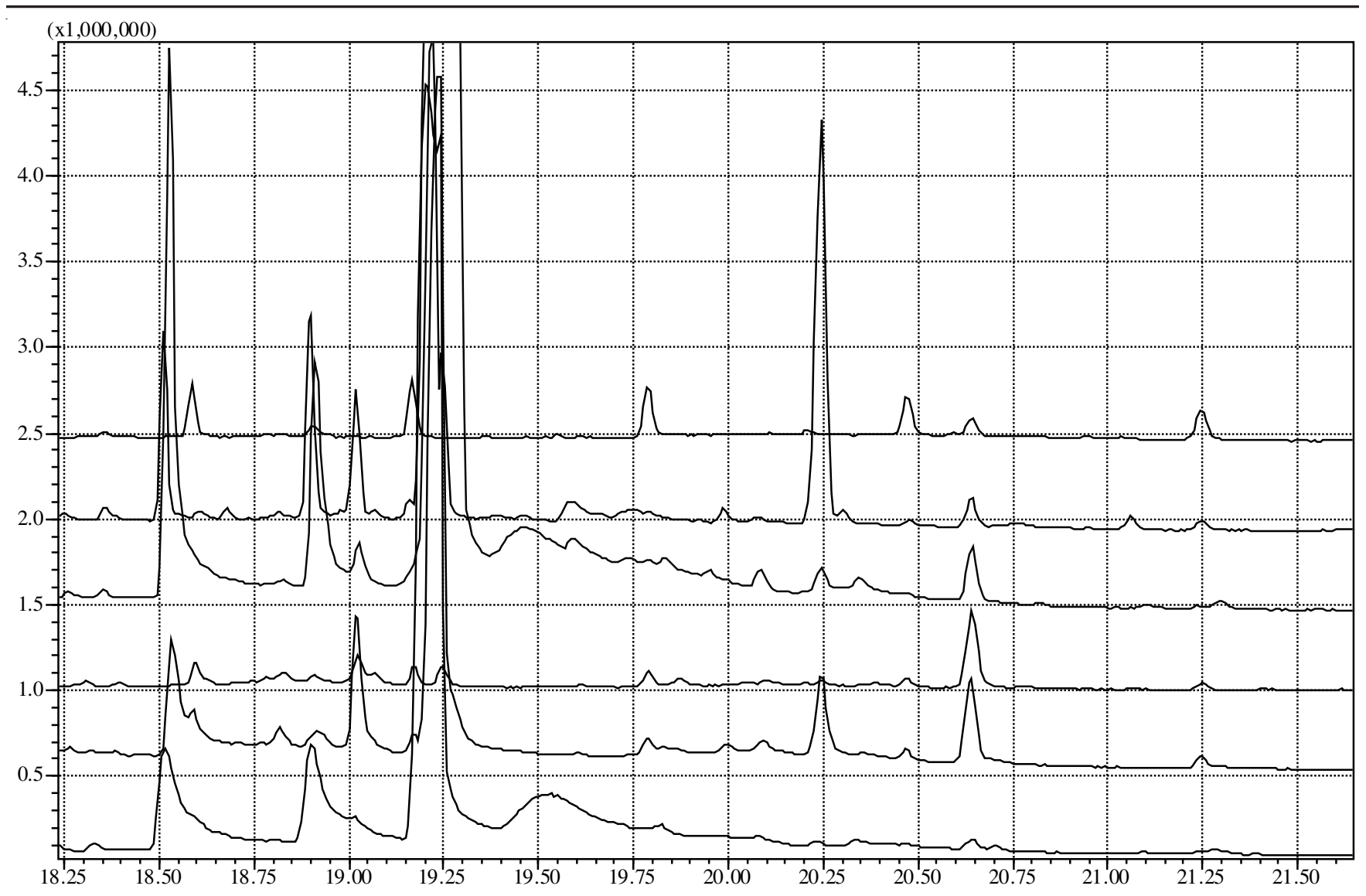

Fig. 3. Comparison chart of the six silanized samples-squalene-total ion current (TIC) chromatogram
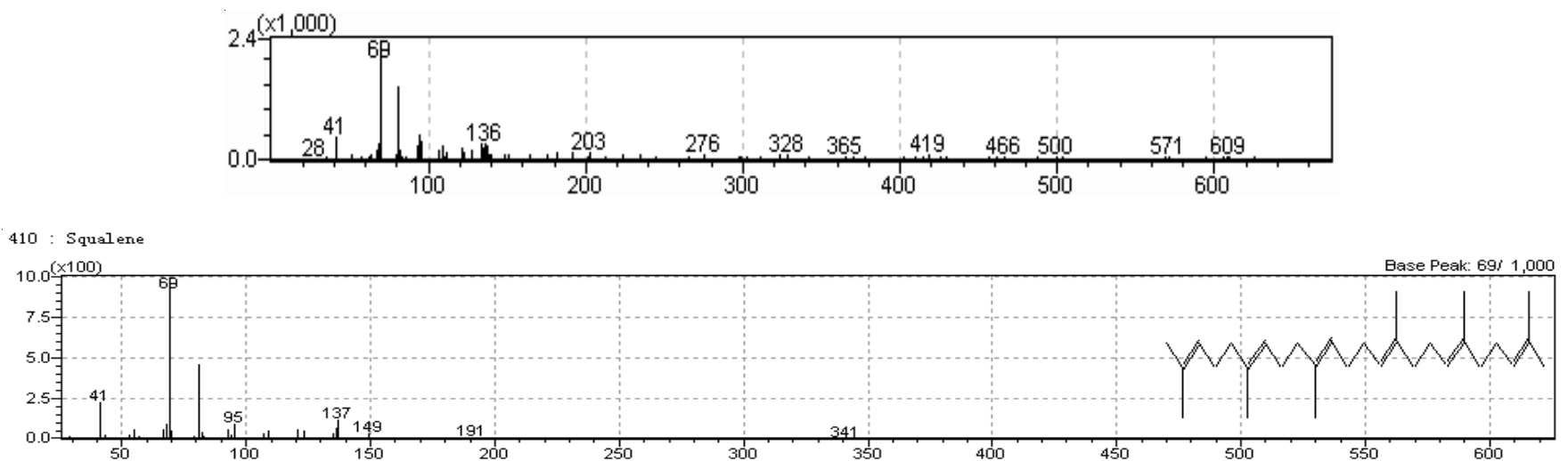

Fig. 4. Squalene chromatogram peak corresponds to the mass spectra and squalene standard mass spectrum

The main components of pepper seeds are $\alpha$-hydroxypropionic acid, glycerol, glucose acid, 21 carbon fatty acid, disaccharide, squalene, etc. Ingredients of different origin pepper seeds are quite different. Squalene has a development value, apparent contrast from the figure, the squalene content in Sichuan pepper seed is higher than that in Shanxi pepper seed.

\section{ACKNOWLEDGEMENTS}

This work was supported by Institute of Chemistry, Chinese Academy of Sciences.

\section{REFERENCES}

1. F.G. Kitson, B.S. Larsen and C.N. McEwen, Gas Chromatography and Mass Spectrometry; A Practical Guide, New York; Academic Press (1998).

2. X.M. Guo, R.E. Sturgeon, Z. Mester and G. Gardner, J. Appl. Organomet. Chem., 17, 575 (2003).

3. P. Jitaru, H.G. Infante and F.C. Adams, Anal. Chim. Acta, 489, 45 (2003).

4. WH. McFadden, Techniques of Combined Gas Chromatography-Mass Spectrometry Applications in Organic Analysis, New York; John Wiley (1973).

5. X.Y. Lai, F. He and L.H. Wu, China Condiment, 3, 4 (2006).

6. S.L. Peng and F.L. Ding, Pepper Magazine, 1, 26 (2008). 